\title{
On the marine atmospheric boundary layer characteristics over Bay of Bengal and Arabian Sea during the Integrated Campaign for Aerosols, gases and Radiation Budget (ICARB)
}

\author{
Denny P Alappattu ${ }^{1, *}$, D Bala Subrahamanyam ${ }^{1}$, P K Kunhikrishnan ${ }^{1}$, \\ K M Somayaji ${ }^{2}$, G S Bhat ${ }^{3}$, R Venkatesan ${ }^{2}$, C B S DutT ${ }^{4}$, \\ A Bagavath Singh ${ }^{2}$, V K Soni ${ }^{5}$ and A S Tripathi ${ }^{6}$ \\ ${ }^{1}$ Space Physics Laboratory, Vikram Sarabhai Space Centre, Thiruvananthapuram 695 022, Kerala, India. \\ ${ }^{2}$ Indira Gandhi Centre for Atomic Research, Kalpakkam 603 102, Tamil Nadu, India. \\ ${ }^{3}$ Center for Atmospheric and Oceanic Sciences, Indian Institute of Science, Bangalore 560 012, India. \\ ${ }^{4}$ Indian Space Research Organization Head Quarters, Antariksh Bhavan, Bangalore 560 094, India. \\ ${ }^{5}$ India Meteorological Department, Pune 411 005, India. \\ ${ }^{6}$ India Meteorological Department, Mausam Bhavan, Lodhi Road, Delhi 110 003, India. \\ *e-mail: dennyalp@gmail.com
}

Detailed measurements were carried out in the Marine Atmospheric Boundary Layer (MABL) during the Integrated Campaign for Aerosols, gases and Radiation Budget (ICARB) which covered both Arabian Sea and Bay of Bengal during March to May 2006. In this paper, we present the meteorological observations made during this campaign. The latitudinal variation of the surface layer turbulent fluxes is also described in detail.

\section{Introduction}

Investigation of Marine Atmospheric Boundary Layer (MABL) and its dynamics, which governs ocean-atmosphere interaction, is imperative for coupled ocean-atmosphere modelling and numerical weather prediction. Moreover, atmospheric momentum flux drives the ocean currents and ocean surface mixing, and thereby determines wave formation over the ocean surface. It is also understood that the momentum flux along with surface energy and fresh water fluxes control the Sea Surface Temperature (Zeng et al 1997). However, the open ocean measurements of MABL and surface layer turbulent fluxes are generally difficult due to unavailability of a stable platform over the oceanic surface. In addition to this, the cost involved in such measurements over the ocean is much higher than that needed for land-based experiments.
In spite of all the criticalities and challenges in conducting the MABL measurements mentioned above, several efforts have been made to characterize the MABL structure and its dynamics in the last few decades. An earliest measurement of open ocean atmospheric surface layer momentum flux was reported by Sheppard and Omar (1952). The first experiments to investigate the MABL were based on pilot balloon ascents made from ships of opportunity crossing the Atlantic Ocean (Hasse 1990). Major field experiments conducted over tropical Pacific and Atlantic Oceans include the Barbados Oceanographic and Meteorological Experiment (BOMEX-1969) (Davidson 1974) Atlantic Trade Wind Experiment (ATEX-1969) (Dunckel et al 1974), Global atmospheric research program Atlantic Tropical Experiment (GATE) (Hasse et al 1975). Humidity Exchange Over Sea (HEXOS 1986) program (DeCosmo et al 1996

Keywords. Atmospheric science; experiments; data analysis. 
and references therein), Tropical Ocean Global Atmosphere (TOGA), TOGA and Coupled Ocean Atmosphere Response program (TOGA-COARE) (Fairall et al 1996). An over view of all these experiments were given by Smith et al (1996).

The first co-ordinated multinational campaign conducted to study MABL over the tropical Indian Ocean region, was the International Indian Ocean Experiment (IIOE) (Ramage 1966; Desai 1970). During this experiment, radiosonde ascends from the ships and dropsondes from aircrafts were made. However, the IIOE data were inadequate to delineate the different sub-layers and characteristics of the MABL over this region. Other major international experiments conducted over the Arabian Sea (AS) and Bay of Bengal (BoB) includes the MONSOON-77 (Mohanty and Das 1986), MONEX-79 (Fein and Kuettner 1980). Recent expeditions over this region were Indian Ocean Experiment (INDOEX, 1996-1999) (Ramanathan et al 1996; Ramana et al 2004) which investigated the physical and chemical properties of aerosols and their radiative forcing over Indian Ocean and Bay of Bengal Monsoon Experiment (BOBMEX, July-August 1999) which was conducted to study the organized convection over the bay (Ramana et al 2000; Bhat et al 2001). These observations helped to broaden our understanding on MABL processes and ocean-atmosphere coupling processes.

\section{Integrated Campaign for Aerosols, gases and Radiation Budget (ICARB)}

The ICARB experiment was conducted under the ISRO Geosphere-Biosphere Program (IGBP) and focused on the physical and chemical characterization of atmospheric aerosols as well as their transport over the Indian landmass and its adjoining oceanic regions thereby evolving an empirical model for the aerosol radiation budget. In view of these objectives, the ICARB experiment was envisaged to address the spatio-temporal distribution of atmospheric aerosols and trace gases over the Indian subcontinent and surrounding waters. As part of this field experiment, extensive measurements of meteorological parameters were carried out onboard Oceanic Research Vessel (ORV) Sagar Kanya during the pre-monsoon season spanning a period of about two months from March to May 2006. In this research paper, we make use of these meteorological measurements taken over the BoB and AS regions for characterization of MABL by estimation of various atmospheric boundary layer parameters and surface layer turbulent fluxes.

The ocean segment of ICARB field experiment was divided into two phases: the first phase

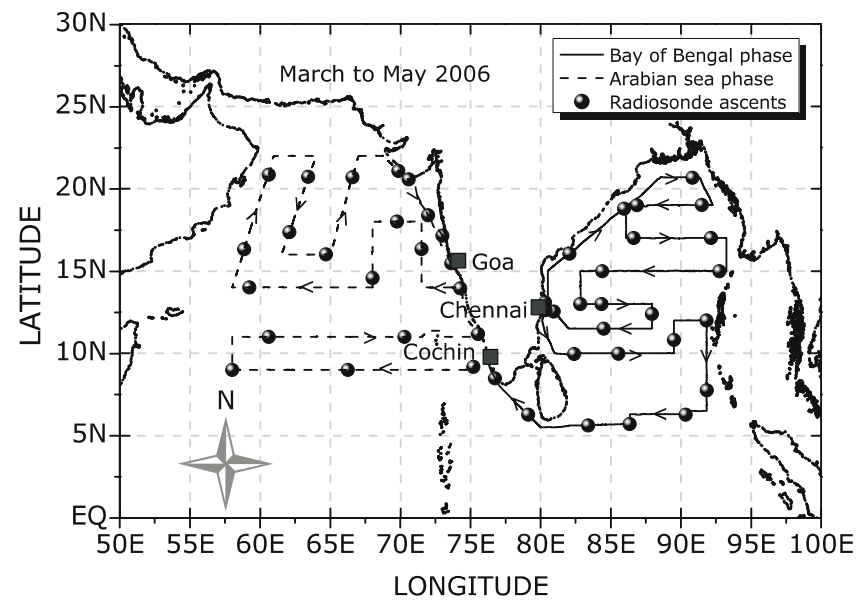

Figure 1. Cruise track of the Integrated Campaign for Aerosols, gases and Radiation Budget (ICARB) field experiment. Dots show the locations from where radiosonde ascents were made.

designated as SK223A covered the $\mathrm{BoB}$ and northern Indian Ocean (NIO). This phase started on 18 March 2006 from Chennai $\left(13.1^{\circ} \mathrm{N}, 78.3^{\circ} \mathrm{E}\right)$ and ended on 13 April 2006 at Kochi port $\left(9.96^{\circ} \mathrm{N}\right.$, $\left.76.27^{\circ} \mathrm{E}\right)$. In continuation to this phase, after a stay of about 5 days in Kochi Port, the second phase of ICARB, namely - SK 223B started on 18 April 2006 from Kochi and concluded on 11 May 2006 at Goa $\left(15.48^{\circ} \mathrm{E}, 73.06^{\circ} \mathrm{E}\right)$. The field experiment confined to the $\mathrm{BoB}, \mathrm{AS}$ and some part of the NIO provided a broad latitudinal and longitudinal coverage between $7^{\circ} \mathrm{N}$ and $22^{\circ} \mathrm{N}$ in latitude and $55^{\circ} \mathrm{E}$ to $75^{\circ} \mathrm{E}$ in longitude. Two phases of the ship-borne field experiment (SK223A and SK223B) are shown as solid and dashed lines respectively in figure 1 . This paper discusses the variability observed in the MABL observed north BoB and south BoB, Indian Ocean, north AS and south AS regions. We also report the latitudinal variation of surface layer turbulent fluxes over the ICARB domain, estimated using the bulk aerodynamic relations.

\section{Experiments and database}

During the campaign extensive measurements of meteorological parameters and upper air measurements were made. Surface layer measurements were recorded using sensors (for measuring temperature, relative humidity, wind speed and wind direction), which were kept at $5 \mathrm{~m}$ and $10 \mathrm{~m}$ above mean sea level mounted on a boom fixed at the bow of the ship. Two automatic weather stations were operated on either side of the ship $(15 \mathrm{~m}$ above mean sea level) to record the meteorological data including total rain and the duration of sunshine. Apart from this, manual measurements of dry and wet bulb temperatures, pressure, wind 
Table 1. Accuracies of various sensors used in the experiment.

\begin{tabular}{|c|c|c|c|c|}
\hline Sl. no. & Parameter & Sensor & Range & Accuracy \\
\hline 1 & Temperature & $\begin{array}{l}\text { Platinum resistance } \\
\text { thermometer }\end{array}$ & $-44^{\circ} \mathrm{C}$ to $52.5^{\circ} \mathrm{C}$ & $1.11^{\circ} \mathrm{C}$ \\
\hline 2 & Humidity & Polymer resistor & 0 to $95 \%$ & $5 \%$ \\
\hline 3 & Wind speed & Cup Anemometer & $1 \mathrm{~m} \mathrm{~s}^{-1}$ to $96 \mathrm{~m} \mathrm{~s}^{-1}$ & $0.1 \mathrm{~m} \mathrm{~s}^{-1}$ \\
\hline 4 & Wind direction & $\begin{array}{l}\text { Potentiometric wind } \\
\text { direction vane }\end{array}$ & 0 to $360^{\circ}$ & $\begin{array}{l}\text { Potentiometer linearity } \\
\text { within } 1 \%\end{array}$ \\
\hline
\end{tabular}

speed, and wind direction were also made using hand-held devices. Sea Surface Temperature (SST) data were collected every 3 hours using the bucket measurements. Table 1 gives the details of various sensors used for the observations during the campaign. Upper air observations were made by highresolution radiosonde (Vaisala RS-92) ascents. A total of 48 ascents were made (on an average of one ascent per day). To investigate the thermal structure and wind pattern, a mini-sodar (Scientec, USA) was operated onboard ORV Sagar Kanya.

Ship-borne measurements of temperature, humidity and wind often experience contamination due to the moisture and heat originating from the exhaust of the ship and flow distortion due to the bulk of the ship (Blanc 1987). These contaminations can be reduced considerably by keeping the sensors as away as possible from the ship body, and these precautions were taken to a large extent by mounting the meteorological sensors on two levels $(5 \mathrm{~m}$ and $10 \mathrm{~m}$ from mean sea level) on a $7 \mathrm{~m}$ long retractable boom fixed at the bow of the ship, quite away from the ship exhaust. The measured wind speed and direction were corrected for the velocity of the ship using the method proposed by Smith et al (1999).

\section{Variation of meteorological parameters during ICARB}

The entire campaign was executed during the premonsoon season. It should be noted here that even though the entire cruise spanned a period of nearly two months, we were not able to investigate the monthly variation of the MABL parameters, since the spatial variability was also inherent. Sky was clear during most days of the cruise barring a few days, while the ship was closer to the Andaman and Nicobar Islands, where the sky was cloudy for most of the time. Another important meteorological observation over the study domain was low to moderate wind speeds along the cruise track. Figure 2(a and $\mathrm{b})$ shows the mean wind pattern obtained from the NCEP/NCAR reanalysis corresponding to the BoB and AS phases of the campaign. From figure $2(\mathrm{a})$, it can be seen that the
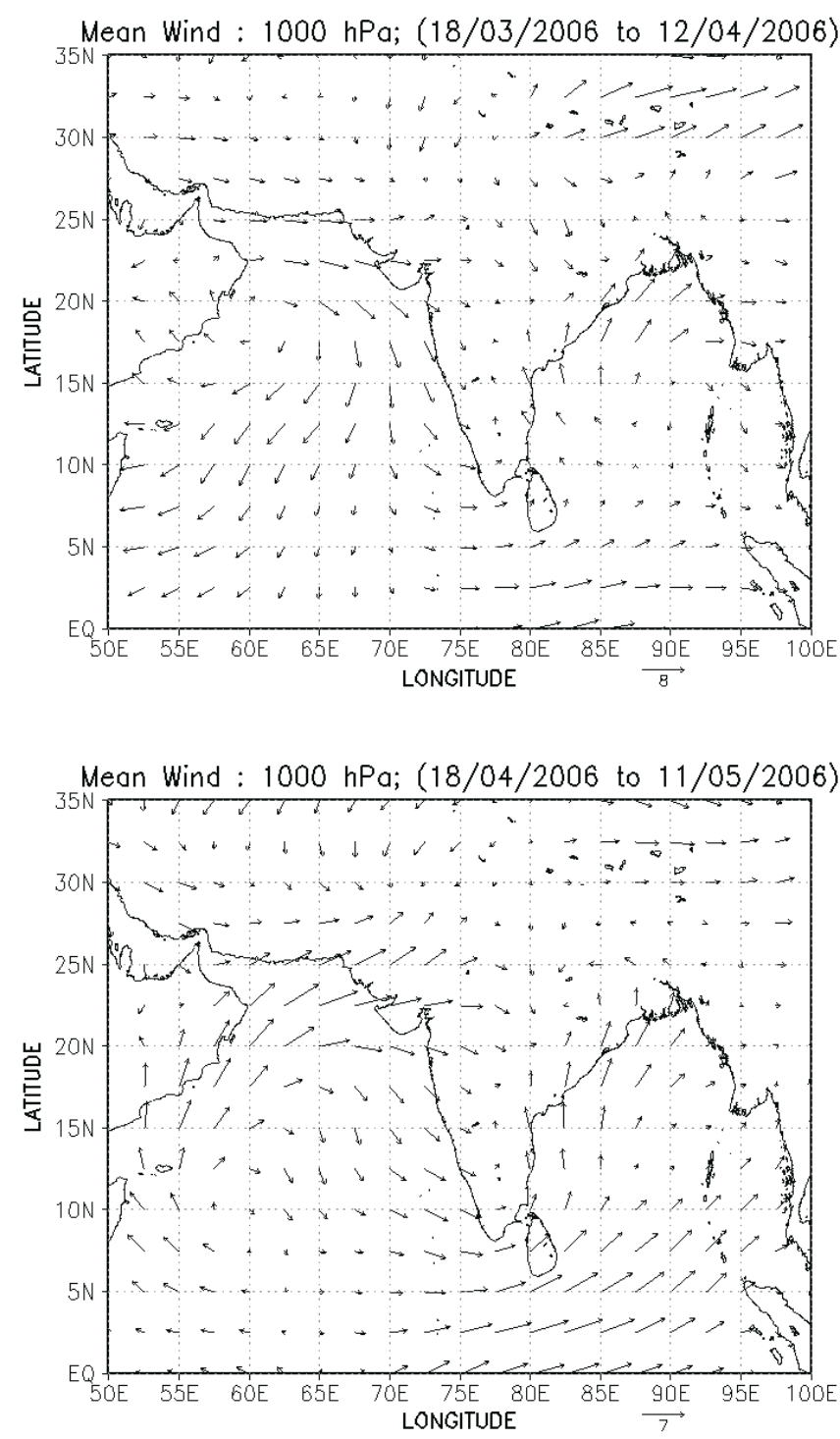

Figure 2. Mean wind vectors during (a) Bay of Bengal phase and (b) Arabian Sea phase of ICARB experiment.

winds were low in the central BoB. During the second phase of campaign over the AS, north-westerly winds were seen over the southern part of the AS, while south-westerly winds were dominant over the northern AS (figure 2b). It may be noted that these figures provide only the synoptic conditions that prevailed during the campaign period. While the 


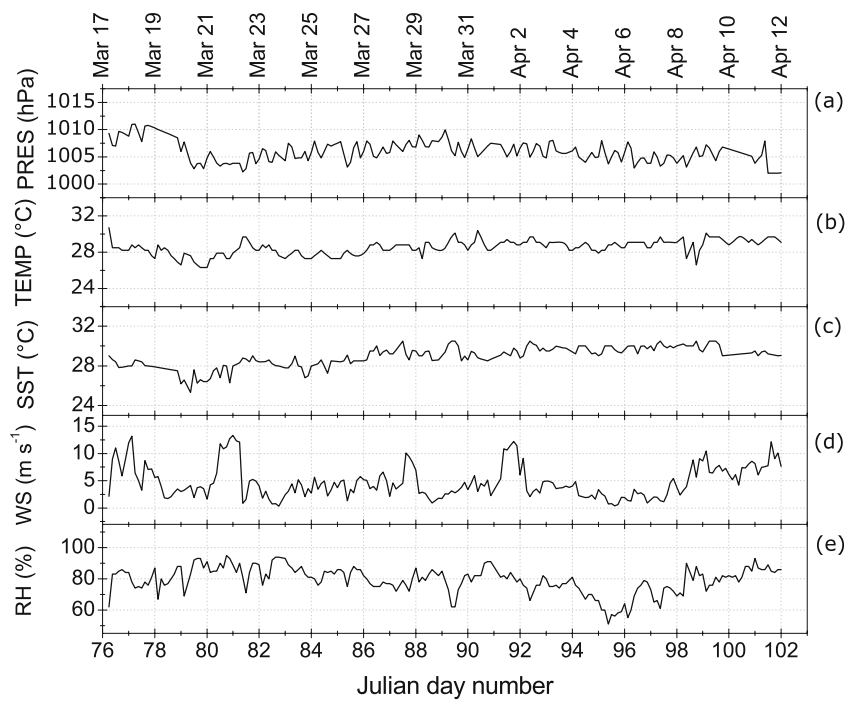

Figure 3. Variation of (a) pressure, (b) temperature, (c) sea surface temperature (SST), (d) wind speed and (e) relative humidity during Bay of Bengal (BoB) phase of ICARB field experiment.

ship was surveying the NIO region (06/04/2006 to $11 / 04 / 2006$ ) the weather was disturbed with moderate to heavy rain. Due to this, the transition layer as well as the trade wind inversion layer was not discernable from the MABL profiles obtained from radiosonde ascents. This aspect is discussed in detail in section 5 .

Figure 3(a-e) shows the variation in meteorological parameters - pressure, temperature, SST, wind speed and relative humidity respectively during the BoB phase of the ICARB field experiment. SST measurements were taken using the bucket thermometer from few centimeters below the sea surface. From figure 3(b) we can see that during the $\mathrm{BoB}$ phase, temperature remained between $27^{\circ} \mathrm{C}$ and $29^{\circ} \mathrm{C}$ during most of the days, with very little diurnal variations till Julian day (JD) 96. Airtemperatures were greater than $29^{\circ} \mathrm{C}$ on JDs 76 , 81, 89, 90 and after JD 96 and JD 98, the temperature values again dropped to $26.6^{\circ} \mathrm{C}$.

On most of the days, it is found that SST is greater than air temperature (figure 3c). On JD 79 , a dip is observed in SST to $25.3^{\circ} \mathrm{C}$. Another decrease to $26.2^{\circ} \mathrm{C}$ is observed on JD 80 . Afterwards, SST remained nearly constant around $28^{\circ} \mathrm{C}$ till JD 82, and on the next day SST again decreased to $26.8^{\circ} \mathrm{C}$. An increase to $30.5^{\circ} \mathrm{C}$ was observed on JD 89. But after JD 90, we can see that, the variation in SST was between $29^{\circ} \mathrm{C}$ and $30.5^{\circ} \mathrm{C}$ till the end of the BoB phase.

Wind speed shows considerable fluctuations from the beginning of the cruise (figure $3 \mathrm{~d}$ ). On JD 77 , wind speed went up to $11 \mathrm{~ms}^{-1}$. Another increase in wind speed can be observed on JDs 80 and 81 recording a maximum of $13 \mathrm{~ms}^{-1}$. After a spell of low winds (during which wind speed was as low as $5 \mathrm{~ms}^{-1}$ ) an increase of $12.2 \mathrm{~ms}^{-1}$ was recorded on JD 91. Towards the end of the cruise wind speed showed a marginal increase. Relative humidity showed considerable fluctuations during the $\mathrm{BoB}$ phase of the ICARB field experiment (figure 3e). It increased up to $95 \%$ on JD 80 and recorded a minimum of $51 \%$ on JD 95. A summary of these variations in meteorological parameters during the $\mathrm{BoB}$ phase is given in table 2 .

Figure 4(a-e) shows the variation in meteorological parameters during the AS phase of the expedition. Comparing figure 4(a) with 3(a), it can be seen that in general, the pressure was more over AS, than that over BoB. Maximum and minimum values of pressure recorded over AS was $1016 \mathrm{mb}$ and $1005.8 \mathrm{mb}$ respectively with an average of $1011 \mathrm{mb}$. Figure 4(b) shows the variation of temperature. Difference between maximum and minimum temperatures during the AS phase was $2.4^{\circ} \mathrm{C}$, the mean value of surface temperature being $28.7^{\circ} \mathrm{C}$. This is not much different from the mean value over $\mathrm{BoB}\left(28.5^{\circ} \mathrm{C}\right)$. The $\mathrm{SST}$ variation is shown in figure 4(c), which shows fluctuations only during the beginning of the AS phase. Average value of SST was $29.3^{\circ} \mathrm{C}$, which is $0.6^{\circ} \mathrm{C}$ greater than the air temperature. The wind speed variation is shown in figure $4(\mathrm{~d})$. Although the maximum wind speed at $10 \mathrm{~m}$ height during the AS phase was lower than that over $\mathrm{BoB}$, average value of wind speed is the same, i.e., $4.8 \mathrm{~ms}^{-1}$. Figure $4(\mathrm{e})$ is the variation of relative humidity over AS during the campaign period. Relative humidity fluctuated between $59 \%$ and $95 \%$ with an average value of $78.5 \%$, which is comparable to the average value of relative humidity estimated for $\mathrm{BoB}(79.2 \%)$. The variation in meteorological parameters during the AS phase is summarized in table 3 .

\section{Upper air observations using radiosonde ascents}

It is well known that the tropical marine atmosphere is different in several respects from those of extra-tropical regions. Tropical marine atmosphere is convectively unstable in the lower and mid troposphere and it warms up continuously through the heat exchange at air-sea interface and through radiative processes, and shows marked spatial variability depending on the ocean dynamics. These aspects are investigated in detail using the radiosonde observations. To understand the spatial variability in more detail, the $\mathrm{BoB}$ and $\mathrm{AS}$ regions are again subdivided into north $\mathrm{BoB}$ and south $\mathrm{BoB}$, and north $\mathrm{AS}$ and south $\mathrm{AS}$ with $15^{\circ} \mathrm{N}$ latitude as the line of separation and the typical profiles from these five regions viz., north $\mathrm{BoB}$, 
Table 2. Table showing minimum, maximum, mean and standard deviation of meteorological parameters and surface layer fluxes during the Bay of Bengal phase.

\begin{tabular}{lrcccc}
\hline \multicolumn{1}{c}{ BoB phase } & Mean & Minimum & Maximum & Location of maximum \\
\hline Pressure $(\mathrm{hPa})$ & 1006.0 & 1002 & 1011 & 16.05 & 82.03 \\
Temperature $\left({ }^{\circ} \mathrm{C}\right)$ & 28.5 & 26.3 & 30.7 & 13.08 & 80.28 \\
SST $\left({ }^{\circ} \mathrm{C}\right)$ & 28.9 & 25.3 & 30.5 & 11.50 & 84.05 \\
Wind speed $\left(\mathrm{m} \mathrm{s}^{-1}\right)$ & 4.8 & 0.3 & 13.3 & 18.99 & 88.44 \\
RH $(\%)$ & 79.2 & 51 & 95 & 19.00 & 89.47 \\
\hline
\end{tabular}

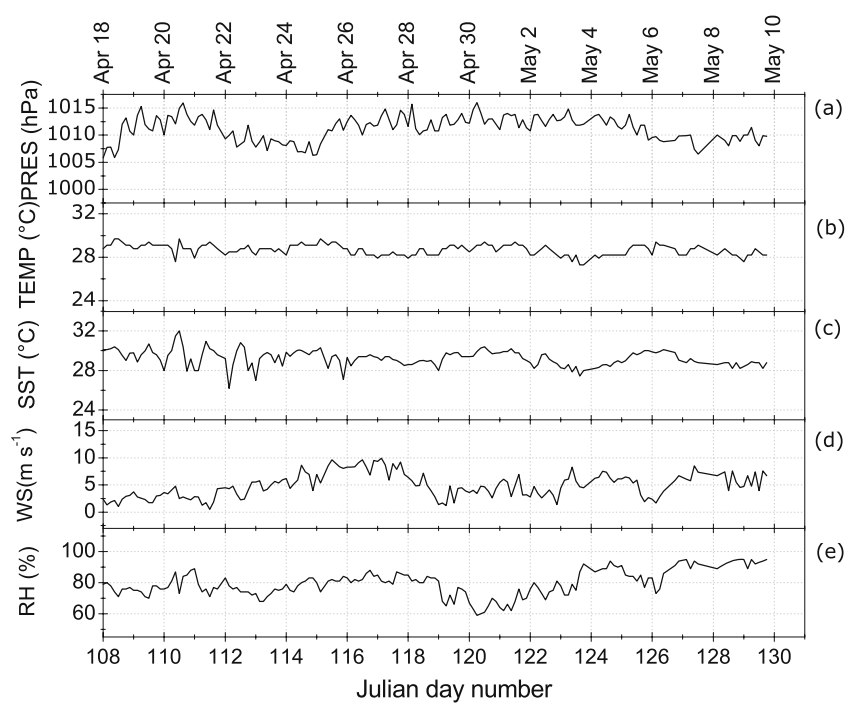

Figure 4. Same as figure 3, but for the Arabian Sea phase of ICARB field experiment.

south BoB, Indian Ocean, south AS and north AS are examined.

Figure 5 shows the typical vertical profiles of virtual potential temperatures $\left(\theta_{v}\right)$ (bottom $x$-axis, solid lines) and saturated equivalent potential temperatures $\left(\theta_{\mathrm{ES}}\right)$ (top $x$-axis, dotted lines) for these five regions. The latitude and longitude of the location where these observations were made are also given in the figure.

Usually over tropical regions, marine lower atmosphere is characterized by different regions such as surface layer, mixed layer (ML), transition layer, cloud layer, and trade wind inversion. The cause of the trade wind inversion is the presence of the descending limb of the Hadley cell circulation. The trade wind inversion, acts as an interface between the cloud layer and the free atmosphere, and is marked by the maximum value of $\theta_{E S}$ (Betts and Albrecht 1987).

Top of the mixed layer is often identified from the virtual potential temperature $\left(\theta_{v}\right)$ profiles (Holt and Raman 1986; Garratt 1992; Parasnis and Morwal 1993; Lambert et al 1999; Subrahamanyam et al 2003). Within the mixed layer due to turbulent mixing of heat as well as moisture, $\theta_{v}$ and specific humidity $(q)$ remain constant and hence $\theta_{v}$ does not vary more than $2 \mathrm{~K} \mathrm{~km}^{-1}$ (Parasnis and Morwal 1993). But above the mixed layer $\theta_{v}$ shows an abrupt change in magnitude. The altitude where this sharp gradient occurs in $\theta_{v}$ is generally considered as the mixed layer height (Stull 1991; Satyanarayana et al 2001). In figure 5(a) (corresponding to north $\mathrm{BoB}$ ) an inversion in virtual potential temperature at an altitude of $\sim 850 \mathrm{~m}$ can be observed which corresponds to the ML height. The narrow altitude region above the top of the ML, with positive temperature gradient represents the transition layer, and the region above this is the cloud layer, which extends up to the trade wind inversion. A unique feature, which is seen in this profile, is the presence of the 'double mixed layer'. Presence of a similar feature over central AS region was earlier reported by Subrahamanyam and Ramachandran (2003b). In figure 5(b) (corresponding to south $\mathrm{BoB}$ ) this inversion is seen at $\sim 855 \mathrm{~m}$. Radiosonde ascent corresponding to the profiles in figure 5(c) was made when the ship was at south eastern side of Sri Lankan island (see cruise track in figure 1). In this profile the inversion feature (the top of the ML) is not visible. It should be noted here that the weather on this day was comparatively disturbed with cloudy sky and rains. Hence, it is conjectured that the strong convection, which would have been prevailing throughout the BL, would have surpassed the inversion, making the temperature gradients less, thus making the inversion feature barely visible.

The ML top is at $\sim 660 \mathrm{~m}$ in figure $5(\mathrm{~d})$ (corresponds to the south AS). Figure 5(e) shows the profiles of $\theta_{v}$ and $\theta_{\mathrm{ES}}$ corresponding to the north AS. Interestingly, the altitude variation of $\theta_{v}$ as well as $\theta_{\mathrm{ES}}$ over north $\mathrm{AS}$ is very different from those corresponding to the other regions. In this region ML height is very shallow $(\sim 420 \mathrm{~m})$ and gradient at the inversion is very sharp compared to the other profiles. This exhibits a wellmixed bottom layer capped by a strong inversion. From the figure $5(\mathrm{a}-\mathrm{e})$, it can also be noted that a well-marked trade wind inversion is visible only in 
Table 3. Same as table 2, but for the Arabian Sea phase of ICARB.

\begin{tabular}{lrrrrr}
\hline \multicolumn{1}{c}{ AS phase } & Mean & Minimum & Maximum & \multicolumn{2}{c}{ Location of maximum } \\
Latitude & Longitude \\
\hline Pressure $(\mathrm{hPa})$ & 1011.0 & 1005.8 & 1016 & 13.99 & 64.51 \\
Temperature $\left({ }^{\circ} \mathrm{C}\right)$ & 28.7 & 27.3 & 29.7 & 9.19 & 75.23 \\
SST $\left({ }^{\circ} \mathrm{C}\right)$ & 29.3 & 26.2 & 32.0 & 9.01 & 61.17 \\
Wind speed $\left(\mathrm{m} \mathrm{s}^{-1}\right)$ & 4.8 & 0.5 & 9.9 & 15.29 & 71.50 \\
$\mathrm{RH}(\%)$ & 78.5 & 59 & 95 & 19.66 & 66.23 \\
\hline
\end{tabular}

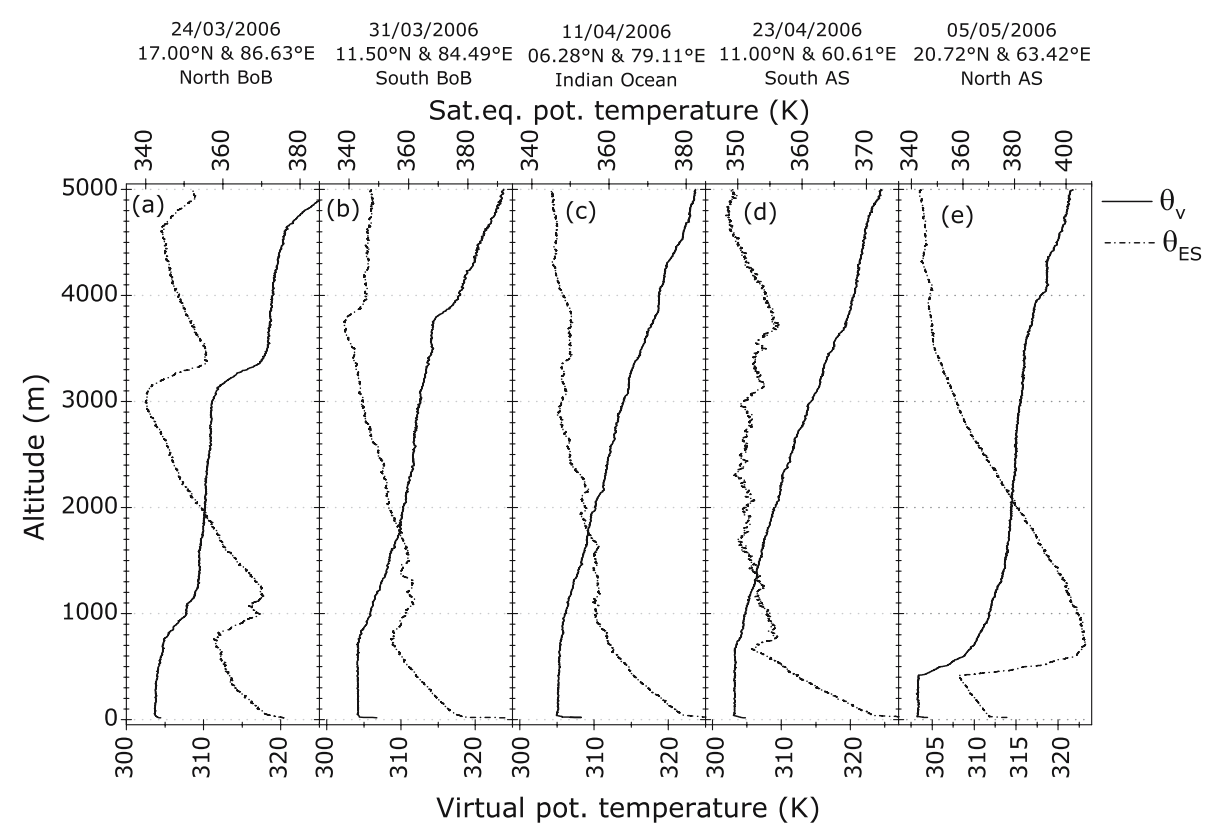

Figure 5. Typical vertical profiles of virtual potential temperatures $\left(\theta_{v}\right)$ and (bottom $x$-axis, solid lines) and saturated equivalent potential temperatures $\left(\theta_{\mathrm{ES}}\right)$ (top $x$-axis, dotted lines) for north Bay of Bengal, south Bay of Bengal, Indian Ocean, south Arabian Sea and north Arabian Sea.

the profiles corresponding to $\mathrm{BoB}$ region. In north and south $\mathrm{BoB}$ profiles, the trade wind inversion heights are at $3070 \mathrm{~m}$ and $3750 \mathrm{~m}$ respectively.

Another parameter that is significant as far as the ML studies are concerned is the specific humidity $(q)$, which is the ratio of mass of water vapour to mass of total air. Turbulent mixing assures the uniform distribution of moisture in the BL. In MABL specific humidity is usually very high compared to that of BL over land because of the high rate of evaporation. Figure 6(a-e) shows the specific humidity profiles corresponding to the profiles shown in figure $5(\mathrm{a}-\mathrm{e})$. In all the oceanic regions (north BoB, south BoB, Indian Ocean, south AS, and north AS) $q$ is greater than $15 \mathrm{~g} \mathrm{~kg}^{-1}$ in the mixed layer. In the profile corresponding to Indian Ocean region (figure 6c) it can be seen that, above the mixed layer specific humidity decreases (except for an increase in $q$ in the 2000-3000 $\mathrm{m}$ region) and becomes negligible above a height of $3000 \mathrm{~m}$. This kind of an increase in a particular altitude region indicates the presence of clouds. The north AS region (figure 6e) is characterised by the maximum value of specific humidity (more than $17.5 \mathrm{~g} \mathrm{~kg}^{-1}$ ) and a sharp decrease of specific humidity with altitude. Within $200 \mathrm{~m}$ above ML, the specific humidity sharply decreases from $\sim 17.5 \mathrm{~g} \mathrm{~kg}^{-1}$ to less than $1 \mathrm{~g} \mathrm{~kg}^{-1}$. This shows that a stronger inversion was present over north AS which was not present over other regions.

Figure 7 depicts the altitude variation of wind speed (bottom $x$-axis, solid lines) and wind direction (top $x$-axis, open circles), as obtained from radiosonde ascents. In figure $7(\mathrm{a})$ (north $\mathrm{BoB}$ ), maximum wind speed $\left(8.0 \mathrm{~m} \mathrm{~s}^{-1}\right)$ was at $\sim 3100 \mathrm{~m}$ and wind direction was predominantly northerly or northwesterly. In figure $7(\mathrm{~b})$ (south $\mathrm{BoB}$ ) winds were random near to ground. But between $1400 \mathrm{~m}$ and $3400 \mathrm{~m}$ a higher wind speed was observed, which could be attributed to the advection of air from north easterly direction. On the day when the ship was at Indian Ocean (figure 7c) winds 


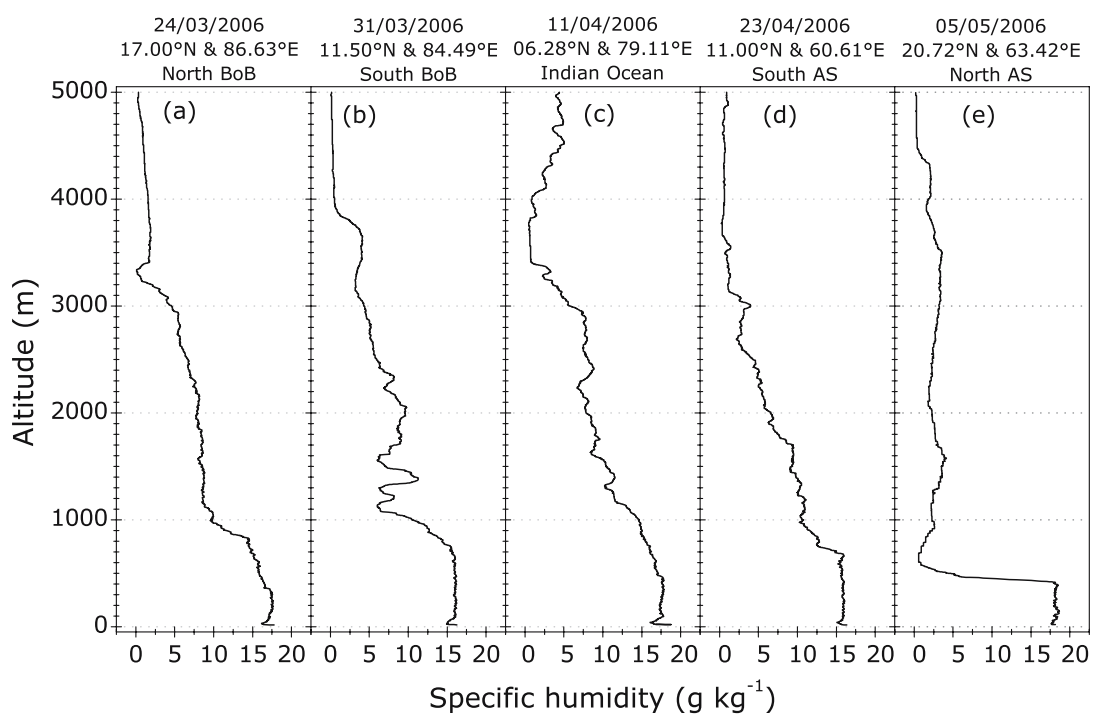

Figure 6. Typical vertical profiles of specific humidity for north Bay of Bengal, south Bay of Bengal, Indian Ocean, south Arabian Sea and north Arabian Sea.

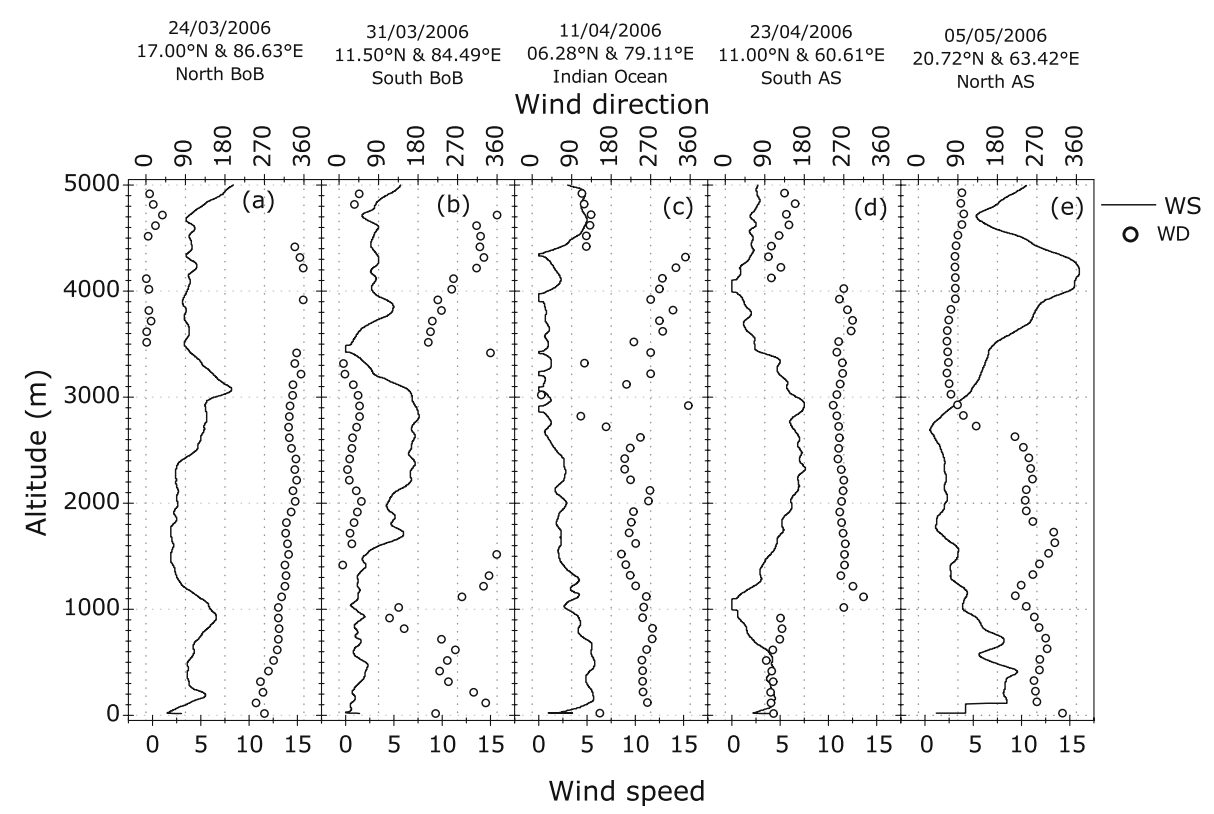

Figure 7. Typical vertical profiles of wind speed $\left(\left(\mathrm{ms}^{-1}\right)\right.$ bottom $x$-axis, solid lines) and wind direction (in degrees, top $x$-axis, open circles) for north Bay of Bengal, south Bay of Bengal, Indian Ocean, south Arabian Sea and north Arabian Sea.

were calm and direction was predominantly southwesterly. Wind speed and direction profiles for the south AS are shown in figure $7(\mathrm{~d})$. It can be seen that in the ML, winds were easterlies, above which advection of wind was from westerly direction. If we analyse the wind profile over north AS (figure 7e) we can see that below $3000 \mathrm{~m}$ winds were south westerlies; above which a strong wind blows from east direction, which peaks to $16 \mathrm{~m} \mathrm{~s}^{-1}$ at an altitude of $4200 \mathrm{~m}$. It should also be noted that among all five profiles wind speed was seen to be maximum at north AS. From the above discussions we can see that north AS region is characterised by the lowest ML depth with a strong inversion and strong winds at higher altitudes. This feature is seen on the profiles observed on JD 118, JD 119, JD 123, JD 126, JD 127 and JD 129. The altitude, where the peak of the strong wind occurs varies considerably $(\sim 2360 \mathrm{~m}$ on JD 118 to $\sim 4800 \mathrm{~m}$ on JD 123). A detailed investigation is needed to understand the underlying phenomena, which drive MABL over the aforementioned oceanic regions especially the peculiar features observed over north AS. 


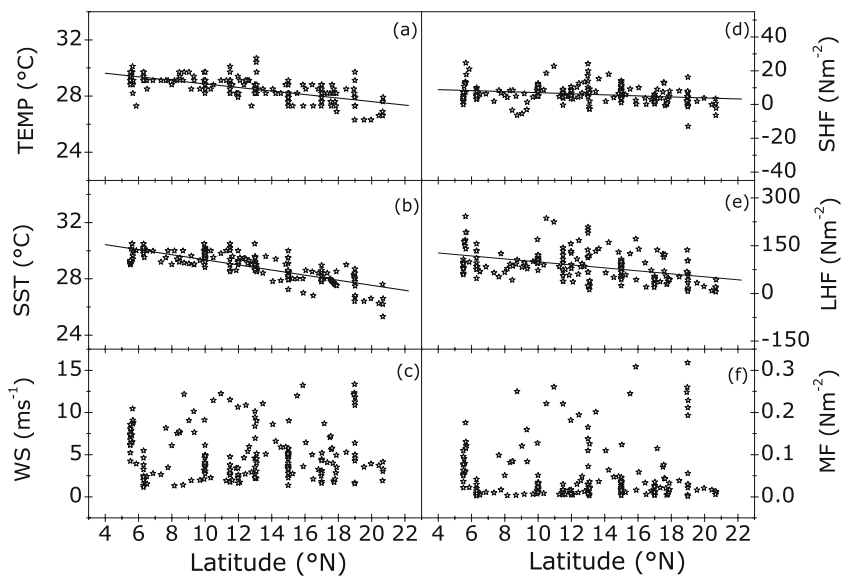

Figure 8. Latitudinal variation of (a) temperature, (b) sea surface temperature, (c) wind speed, (d) sensible heat flux, (e) latent heat flux and (f) momentum flux over Bay of Bengal.

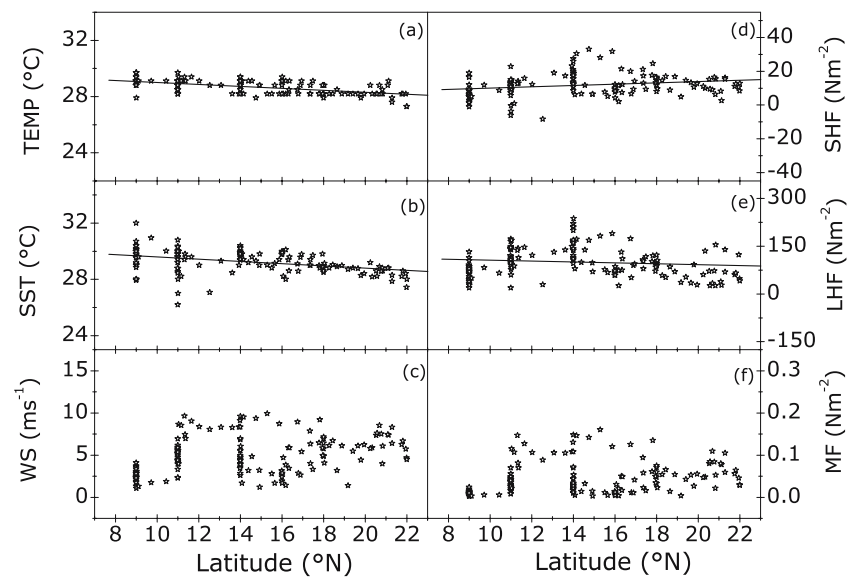

Figure 9. Same as figure 8, but for the Arabian Sea phase.

\section{Latitudinal variation of surface layer fluxes}

Air-sea interface fluxes of momentum, heat and moisture have great significance in MABL studies as well as in the field of oceanography. Direct estimation of these fluxes requires high frequency measurements of meteorological parameters from a stable platform (Dobson et al 1980; Blanc 1983). Empirical methods are adopted for the estimation of surface layer fluxes, the bulk aerodynamic algorithm being one among them. Zeng et al (1997) gave an inter-comparison of various bulk aerodynamic algorithms using the TOGA COARE ship and multiyear hourly TOGA buoy data. Estimated fluxes using six different algorithms show good agreement under moderate wind conditions.

In general, these algorithms estimate the turbulent exchanges of downward momentum flux or stress $(\tau)$ in $\mathrm{Nm}^{-2}$, sensible heat flux $\left(H_{S}\right)$ and latent heat flux $\left(H_{L}\right)$ in $\mathrm{Wm}^{-2}$, which involves the

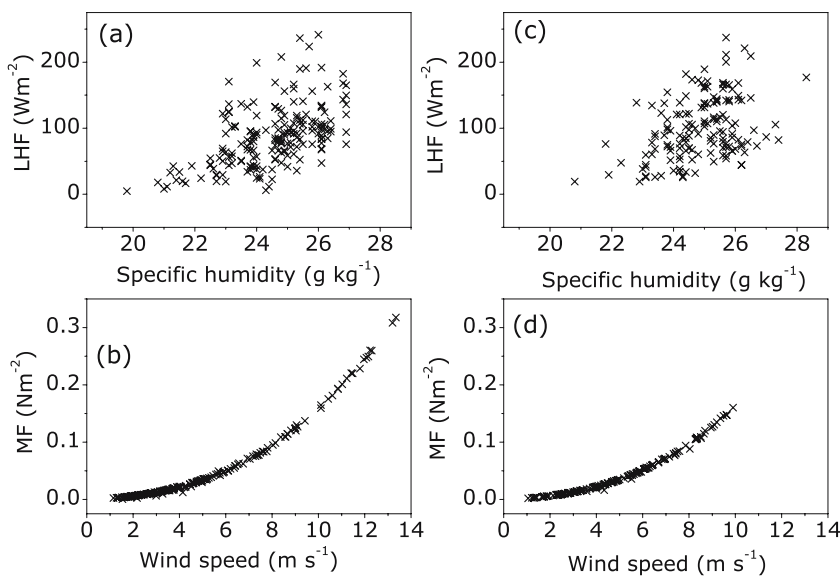

Figure 10. Dependence of latent heat flux and momentum flux on specific humidity and wind speed for ( $\mathbf{a}$ and $\mathbf{b}$ ) Bay of Bengal phase and (c and $\mathbf{d})$ Arabian Sea phase.

computation of drag coefficient $C_{D}$, sensible heat exchange coefficient $C_{H}$ and latent heat exchange coefficient $C_{E}$.

The flux estimation equations are given below:

$$
\begin{aligned}
\tau & =\rho C_{D}\left(U_{10}-U_{s}\right)^{2}, \\
H_{s} & =\rho C_{P} C_{H}\left(U_{10}-U_{s}\right)\left(T_{s}-\theta_{10}\right), \\
H_{L} & =\rho L_{v} C_{E}\left(U_{10}-U_{s}\right)\left(q_{s}-q_{10}\right),
\end{aligned}
$$

where $L_{v}$ is the latent heat of vaporization, $\rho$ is the density of the moist air, $U, \theta$ and $q$ represent the mean wind speed $\left(\mathrm{ms}^{-1}\right)$, potential temperature $(\mathrm{K})$ and specific humidity $\left(\mathrm{kg} \mathrm{kg}^{-1}\right)$ respectively. The subscripts ' $s$ ' and ' 10 ' represent the measurements of the concerned parameter at the sea surface and at a measurement height of $10 \mathrm{~m}$ from the mean sea level respectively and $T_{s}$ is the sea surface temperature $(\mathrm{K})$. Various schemes of determining exchange coefficients are discussed by Blanc (1985). In the present analysis the air-sea interaction fluxes over $\mathrm{BoB}$ and AS are estimated using the bulk aerodynamic algorithm proposed by Smith (1988) and subsequently modified by Subrahamanyam and Ramachandran (2002, 2003a). The details of this algorithm is described elsewhere (Subrahamanyam and Ramachandran 2002, 2003a; Subrahamanyam et al 2007; Alappattu et al 2007).

As mentioned earlier, the computation of the fluxes requires the values of the drag coefficient $C_{D}$, sensible heat exchange coefficient $C_{H}$ and latent heat exchange coefficient $C_{E}$. In the present observation period, the $C_{D}$ values varied from $0.24 \times 10^{-3}$ (corresponding to a wind speed of 
$0.6 \mathrm{~m} \mathrm{~s}^{-1}$ ) to $1.8 \times 10^{-3}$ (corresponding to a wind speed of $1.5 \mathrm{~m} \mathrm{~s}^{-1}$ ). Similarly the values $C_{E}$ and $C_{H}$ varied from $0.23 \times 10^{-3}$ to $2.2 \times 10^{-3}$.

Figure $8(\mathrm{a}-\mathrm{f})$ shows the latitudinal variation of air temperature measured at an altitude of $10 \mathrm{~m}$ from the mean sea level, sea surface temperature (SST) measured by bucket measurements, wind speed at $10 \mathrm{~m}$ altitude from the mean sea level, and fluxes of sensible heat, latent heat and momentum estimated by bulk aerodynamic relations. It can be seen from figure 8(a) and (b) that air temperature and SST decreases with increasing latitude. The latitude variation of LHF (figure 8e) shows similar variation as that of air temperature and SST over the BoB. Higher SSTs would tend to increase the evaporation rate from the ocean surface, which in turn increases the LHF. Sensible heat flux (figure 8d) also shows the decreasing trend towards the higher latitudes, but the gradient is not as high as that of LHF. It can be seen from the figures 8(a) and (b) that, even though wind speed and MF show random fluctuations, the $\mathrm{MF}$ and WS show similar variation, which is quite expected.

Latitudinal variations of air temperature, SST, wind speed, fluxes of sensible heat, latent heat and momentum for the AS phase of the campaign are shown in figures $9(\mathrm{a}-\mathrm{f})$. As can be seen from figure 9(a) and (b); air temperature and SST show latitudinal decrease as that observed over the BoB. However, over AS, this gradient is much lower than that observed over BoB. Latitudinal decrease can be observed in the LHF also (figure 9e), but dependence of LHF on SST is not visible over AS (figure $9 \mathrm{~b}$ and e). High LHF values can be observed for high wind speeds, which are caused due to the increased evaporation rates at high wind speeds. But over AS, in contradiction to that observed over $\mathrm{BoB}$, SHF is almost constant or shows only a marginal increase with latitude. As SHF is a function of both air-sea temperature difference and wind speed, wherever the air-sea temperature difference is low, higher wind speeds can cause an increase in SHF. Here also wind speed and MF flux variations are similar (figure 9a and b).

Using the INDOEX-IFP 99 data, the air-sea fluxes of momentum, heat and moisture were computed for the central Arabian Sea and Indian Ocean region $\left(15^{\circ} \mathrm{N}-20^{\circ} \mathrm{S}\right.$ and $\left.63^{\circ} \mathrm{E}-77^{\circ} \mathrm{E}\right)$ corresponding to the period January to March 1999 (Subrahamanyam and Ramachandran 2002). A comparison of the flux estimates over this region, from these two experiments is reported elsewhere (Alappattu et al 2007). It was observed that there are substantial differences in the magnitudes of these fluxes, even though both estimates were made using the same algorithm. This points towards the seasonal dependence of these fluxes, and reiterates the importance of having such coordinated MABL observations in different seasons and longitude sectors.

The dependence of LHF and MF on specific humidity and wind speed measured at $10 \mathrm{~m}$ altitude from mean sea level for $\mathrm{BoB}$ phase and $\mathrm{AS}$ phase are shown in figures 10(a)-(d). LHF shows a steady increase with specific humidity both over $\mathrm{BoB}$ and AS. Dependence of MF on wind speed is quite visible from figures $10(\mathrm{~b})$ and (d) (BoB and AS respectively). Initially for low wind speeds (up to $4 \mathrm{~m} \mathrm{~s}^{-1}$ ), increase in MF is rather slow. But towards higher wind speeds MF linearly increases with wind speed.

\section{Conclusion}

The present study provides the extensive observations of MABL features using radiosonde ascents as well as surface layer measurements using shipborne sensors. The investigation was conducted as a part of the Integrated Campaign for Aerosols, gases and Radiation Budget (ICARB) for a period spanning from March to May 2006, covering both the Bay of Bengal (BoB) and Arabian Sea (AS) regions. In the present paper, the variability of MABL parameters like virtual potential temperature $\left(\theta_{V}\right)$, saturated equivalent potential temperature $\left(\theta_{\mathrm{ES}}\right)$, specific humidity $(q)$, and winds are investigated in detail, for north and south $\mathrm{BoB}$ as well as AS and the northern Indian Ocean regions, using radiosonde profiles. It is found that over north AS, the mixed layer depths were comparatively lower than that over other regions, with the presence of strong inversions. The estimates of bulk transfer coefficients and roughness lengths for velocity, temperature and humidity are also obtained using a modified bulk aerodynamic method. Over AS, the latitudinal variation of SST and LHF shows a decreasing trend with increasing latitude. The latitudinal variation of LHF shows a dependence on SST over BoB region, whereas over AS region, such dependence is not seen. LHF shows a steady increase with specific humidity over both $\mathrm{BoB}$ and $\mathrm{AS}$ regions.

\section{Acknowledgements}

We are grateful to Dr. K Krishna Moorthy, Chief Scientist and Program Co-ordinator, ICARB and all members of the ICARB program for their concerted efforts which made the campaign a grand success. We would like to acknowledge the staff and crew of ORV Sagar Kanya for extending all support and logistics for carrying out the field experiment onboard the ship. We acknowledge NCAOR/DOD 
and Dr M Sudhakar, for the ship and onboard facilities. We also acknowledge NOAA:CDC for providing the NCEP/NCAR reanalysis data through the website http://www.cdc.noaa.gov. One of the authors, Denny P Alappattu, gratefully acknowledges the financial assistance provided by the Indian Space Research Organization (ISRO) through a research fellowship. We would also like to extend our sincere thanks to the anonymous reviewers for their critical comments that improved the content of the paper.

\section{References}

Alappattu D P, Subrahamanyam D B, Kunhikrishnan P K, Ramachandran R, Somayaji K M, Venkatesh R and Bhagavath Singh A 2007 Spatio-temporal variability of surface layer turbulent fluxes over Bay of Bengal and Arabian Sea during ICARB field experiment; BoundaryLayer Meteorol., doi: 10.1007/s10546-007-9233-2, 126 297-309.

Betts A K and Albrecht B A 1987 Conserved variable analysis of the convective boundary layer thermodynamic structure over the tropical oceans; J. Atmos. Sci. 44 83-99.

Bhat G S et al 2001 BOBMEX: The Bay of Bengal Monsoon Experiment; Bull. Amer. Meteor. Soc. 82(10) $2217-2243$.

Blanc T V 1983 A practical approach to flux measurements of long duration in the marine atmospheric surface layer; J. Clim. Appl. Meteorol. 22 1093-1110.

Blanc T V 1985 Variation of bulk-derived surface flux, stability and roughness results due to the use of different transfer coefficient schemes; J. Phys. Oceanogr. 15 650-659.

Blanc T V 1987 Accuracy of bulk-method determined flux, stability and surface roughness; J. Geophys. Res. 92 3867-3876.

Davidson K L 1974 Observational results on the influence of stability and wind-wave coupling on the momentum transfer and turbulent fluctuations over Ocean waves; Boundary Layer Meteorol. 6 305-331.

DeCosmo J, Katsaros K B, Smith S D, Anderson R J, Oost W A, Bumke K and Chadwick H 1996 Air-sea exchange of water vapor and sensible heat: The Humidity Exchange Over the Sea (HEXOS) results; J. Geophys. Res., doi: 10.1029/95JC03796, 101(C5) 12,001-12,016.

Desai B N 1970 Nature of low-level inversion over the Arabian Sea and the role of western ghats in modifying airmass stratification within $500 \mathrm{~km}$ of the west coast of Peninsula; Indian J. Meteorol. Geophys. 21 653-655.

Dobson F W, Hasse L and Davies R 1980 Air sea interaction instruments and methods; Plenum, New York, 801.

Dunckel M, Hasse L et al 1974 Turbulent fluxes of momentum, heat and moisture in the atmospheric surface layer in the sea during ATEX: Atlantic Trade Wind Experiment; Boundary-Layer Meterol. 6 81-106.

Fairall C W, Bradley E F, Rogers D P, Edson J B and Young G S 1996 Bulk parameterization of air-sea fluxes for Tropical Ocean-Global Atmosphere Coupled-Ocean Atmosphere Response Experiment; J. Geophys. Res., doi: 10.1029/95JC03205, 101(C2) 3747-3764.
Fein J S and Kuettner J P 1980 Report on the summer MONEX field phase; Bull. Am. Meteorol. Soc. 61 461-474.

Garrat J R 1992 The atmospheric boundary layer; Cambridge University Press, Cambridge.

Hasse L, Wucknitz J, Kruspe G, Ivanov V M, Shuskv A A et al 1975 Preliminary report on determination of fluxes by direct and profile method during intercomparison II a, GATE report, WMO, Geneva, 14 267-277.

Hasse L 1990 Oceanic micrometeorological field experiments: A historical perspective; Boundary Layer Meteorol. 50 139-146.

Holt T and Raman S 1986 Observations of the mean and turbulence structure of the marine boundary layer over the Bay of Bengal during MONEX-79; Mon. Wea. Rev. $1142176-2190$.

Lambert D, Durand P, Thoumiex F, Benech B and Druilhet A 1999 The marine atmospheric boundary layer during SEMAPHORE. II: Turbulence profiles in the mixed layer; Quart. J. Roy. Meteorol. Soc. 125 $513-528$

Mohanty U C and Das S 1986 On the structure of the atmosphere during suppressed and active period of convection over the Bay of Bengal; Proc. Indian Acad. Sci. 52 625-640.

Parasnis S S and Morwal S B 1993 Thermodynamic structure of the atmospheric boundary layer over the Arabian sea as revealed by MONSOON-77 data; Boundary Layer Meteorol. 63 365-380.

Ramage C S 1966 The summer atmospheric circulation over the Arabian Sea; J. Atmos. Sci. 23 144-150.

Ramana M V, Krishnan P, Nair S M and Kunhikrishnan P K 2004 Thermodynamic structure of the atmospheric boundary layer over Arabian Sea and the Indian Ocean during pre-INDOEX and INDOEX-FFP campaigns; Ann. Geophys. 22 2679-2691.

Ramana M V, Sen Gupta K, Bhat G S, Ameenulla S and Raju J V S 2000 Inertial-dissipation flux measurements over the south Bay of Bengal during BOBMEX-pilot experiment; Proc. Indian. Acad. Sci. (Earth Planet Sci.) $109239-247$.

Ramanathan V et al 1996 Indian Ocean Experiment (INDOEX), A multi-agency proposal for field experiment in the Indian Ocean; Publ. 162, Scripps Inst. Oceanogr., La Jolla, Calif., 1-83.

Satyanarayana A N V, Mohanthy U C, Niyogy D S, Raman S, Lykossov V N, Warrior H and Sam N V 2001 A study on air-sea exchange processes in the ITCZ and non ITCZ regimes over Indian Ocean with INDOEX IFP99 data; Curr. Sci. (suppl.) 80 39-45.

Sheppard P A and Omar M H 1952 The wind stress over the oceans from the observations in the trades; Quart. J. Roy. Meteorol. Soc. 78 583-589.

Smith S R, Bourassa M A and Sharp R J 1999 Establishing more truth in true winds; J. Atmos. Oceanic Technol. 16 939-952.

Smith S D 1988 Coefficients for Sea Surface Wind Stress, Heat Flux and Wind profiles as a Function of Wind Speed and Temperature; J. Geophys. Res. 93 15,467-15,472.

Smith S D, Fairall C W, Geernaert G L and Hasse L 1996 Air sea fluxes: 25 years of progress; Boundary Layer Meteorol. 78 247-290.

Stull S 1991 An introduction to boundary layer meteorology; Kluwer Academic Publishers.

Subrahamanyam D B, Ramachandran R, Sengupta K, Krishnan P, Kunhikrishanan P K and Ravindran S 2003 Variability of the mixed layer heights over Indian Ocean 
and central Arabian Sea during INDOEX-IFP 99; Boundary Layer Meteorol. 107 683-695.

Subrahamanyam D B and Ramachandran R 2002 Air sea fluxes over the Indian Ocean during INDOEX, IFP-99; J. Atmos. Sol. Terr. Phys. 64(3) 291-305.

Subrahamanyam D B and Ramachandran R 2003a Structural characteristics of marine atmospheric boundary layer and its associated dynamics over the Central Arabian Sea during INDOEX, IFP-99 campaign; Curr. Sci. 85(9) 1334-1340.

Subrahamanyam D B and Ramachandran R 2003b Wind speed dependence of air-sea exchange parameters over the Indian Ocean during INDOEX, IFP-99; Ann. Geophys. 21 1-13.

Subrahamanyam D B, Ramachandran R, India Rani S, Kunhikrishnan P K and Prasad Kumar B 2007 Inter comparison of air-sea interface fluxes over the yellow sea and Korea strait: Impact of Thushima warm current; Boundary Layer Meteorol. DOI 10.1007/s10546007-9248-8.

Zeng X, Zhao M and Dickinson R E 1997 Intercomparison of bulk aerodynamic algorithms for the computation of sea surface fluxes using TOGA COARE and TAO data; J. Climate $112628-2644$. 